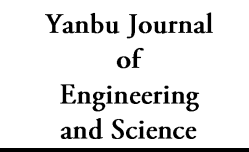

ISSN: $1658-5321$
Vol. 15, December 2017 (1438H) www.yjes.org.sa

\title{
DC MOTOR DRIVE CONTROL USING FUZZY PD+I CONTROLLER BASED GA TUNING
}

\author{
Fawzan Salem ${ }^{1}$ and Mohamed I. Mosaad ${ }^{2}$ \\ ${ }^{1}$ Electronics Research Institute, Egypt, on leave to YIC, Saudi Arabia, \\ ${ }^{2}$ Higher Technological Institute $10^{\text {th }}$ of Ramadan City, Egypt, on leave to YIC, Saudi Arabia \\ E-mail:m_i_mosadd@hotmail.com
}

\begin{abstract}
This article presents a control method for DC motor drive using Fuzzy PD+I controller based Genetic Algorithm (GA). This control method is adequate whenever it is possible to apply a PID controller or this controller is already applied. The idea behind this controller is to adjust a conventional PID control parameters $\left(K_{p}, K_{i}\right.$ and $\left.K_{d}\right)$ using GA and then determine the equivalents of these gains in the fuzzy domain. The tuned controller parameters are used as initial values for parameters of the fuzzy PD+I controller. The proposed controller, fuzzy PD+I controller has the feature to be either linear or non-linear controller to obtain a better performance. Testing the proposed controller for the DC motor drive to control the speed of the motor over a wide range of the operating speed is applied. Moreover, the proposed fuzzy PD+I controller succeeds at improving the system performance even with changing the system parameters.
\end{abstract}

Keywords: Fuzzy PD+I, scaling factors, DC motor drives, Speed Control.

\section{INTRODUCTION}

The DC motor drives are still used in industrial applications where fine speed adjustment is needed. Different control techniques are used to control the speed of the DC drive. There are many methods of speed control of DC motors including field control, armature voltage control, and armature resistance control methods [1]. The most commonly used method of speed control is the armature voltage control thanks to the new developments in the power electronic devices [2]. These power electronic devices used for the speed control of DC motors based armature voltage are mainly electronic converter controllable rectifier or PWM chopper to supply a controllable voltage to the motor.
Consequently, there will be nonlinearity in the motor characteristics. Some new controllers have the ability to deal with the non-linearity in the systems, among them fuzzy logic controllers [3-6]. The performance of fuzzy logic controllers depends mainly on the control rules and the scaling factors. Hence, the optimization of these parameters has been one of the most investigated problems in the theory of fuzzy systems. In many of the fuzzy logic controllers proposed some optimization techniques are used for tuning the parameters [7]. PID controller is still used in abundance in industry as it is characterized by its simplicity structure and robust performance in a wide range of operating conditions. There are many methods for 
tuning the parameters including ZieglerNichols, analytical methods, and evolutionary computing techniques like Genetic Algorithms (GA) and Particle Swarm Optimization (PSO), [8-10]. GA has many applications in electrical systems for optimization applications [8-9]. The fuzzy with certain assumptions has the same performance like PID controllers [4]. This paper presents robust DC motor drive for speed control using Fuzzy PD+I Controller based GA Tuning. GA is used for tuning the PID controller parameters by minimalizing the integral sum of square of error (ISE) between the motor speed and a reference speed. Transferring the obtained optimized PID control into fuzzy PD+I controller by applying input and output scaling factors of the fuzzy PD+I controller to PID control parameters. To test the validity of the fuzzy PD+I through PID controllers at the linear state, no saturation in the system is assumed and the system should have the same response for the two controllers. Another tuning of the scaling factors of the equivalent linear fuzzy $\mathrm{PD}+\mathrm{I}$ controller are performed to transform it into a nonlinear controller. This transformation from linear to nonlinear controller is due to the fact that the greater the nonlinearity variations, the greater the possibility of a high-performance controller [4]. To design a fuzzy PID controller, a three dimension rule base should be established. This enlarges the rule base and complicates the inference engine and the defuzzication process. For this reason, the rule base has a two-dimensional space, the error and the rate of change of error. The integral action is accomplished separately in the non-fuzzy domain in order to construct the rule base on a twodimensional space instead of three. Introducing the non-fuzzy integral branch has the advantage of simplifying the rule base without affecting the controller's overall performance. The DC motor drives are still used in industrial applications where fine speed adjustment is needed.

\section{MATHEMATICAL MODEL OF THE DC MOTOR}

The motor dynamics can be described in the following two equations:

$$
\begin{gathered}
i_{a}^{\cdot}=-\frac{R_{a}}{L_{a}} i_{a}-\frac{K}{L_{a}} \omega+\frac{1}{L_{a}} V_{t} \\
\omega^{\bullet}=\frac{K}{J_{a}} i_{a}-\frac{D}{J_{a}} \omega-\frac{1}{J_{a}} T_{L}
\end{gathered}
$$

Where $i_{a}, \omega, V_{t}, R_{a}, L_{a}, J_{a}, K, D$ and $T_{L}$ are the armature current, rotor speed, terminal voltage, armature resistance, armature inductance, rotor inertia, torque and back emf constant, damping constant and load torque respectively.

\section{THE FUZZY LOGIC CONTROLLER}

When a PID controller is already implemented, it is possible to make use of the known PID controller design before implementing the fuzzy controller. A systematic tuning procedure by carrying PID tuning rules over to the fuzzy domain is as follows:

a. Tuning a PID controller

b. Replacing it with an equivalent linear fuzzy controller

c. Converting the linear fuzzy controller into a nonlinear one

d. Fine tune it

\subsection{TUNING A PID CONTROLLER USING GA}

Genetic algorithms (GAs) are biologically inspired techniques used for optimization. This algorithm encode a potential solution to a specific problem on a simple chromosome like data structure and apply 
recombination operators to these structures so as to preserve critical information [11-13]. The GA begins with defining the optimization variables, the fitness function, and the fitness. It ends by testing for convergence or with the maximum generations. In this paper, the goal of optimization is to find the PID controller parameters that minimize the ISE of the objective function, $J$, defined in (3). The cost function, $\mathrm{J}$, is given by:

$$
\operatorname{ISE}\left(K_{p}, K_{p}, K_{d}\right)=\frac{1}{t} \int_{0}^{t}\left(N_{r e f}-N_{m o t}\right)^{2} d t
$$

Where Nref and Nmot are the reference and motor speeds respectively. In GAs, all of the possible values of the PID control parameters are coded in chromosomes. Series binary coding is used in this work. Next a fitness function (ISE) is calculated with initial value of the controller parameters, to compare the chromosomes which have to be defined. Therefore, to calculate the fitness of a chromosome, the optimization function has to be calculated using the information in the chromosome. Finally the optimization process stopped if the minimum value of fitness function is reached or maximum number of generations is reached [10-12]. The flow chart of GA used for PID controller tuning is given in Figure 1.

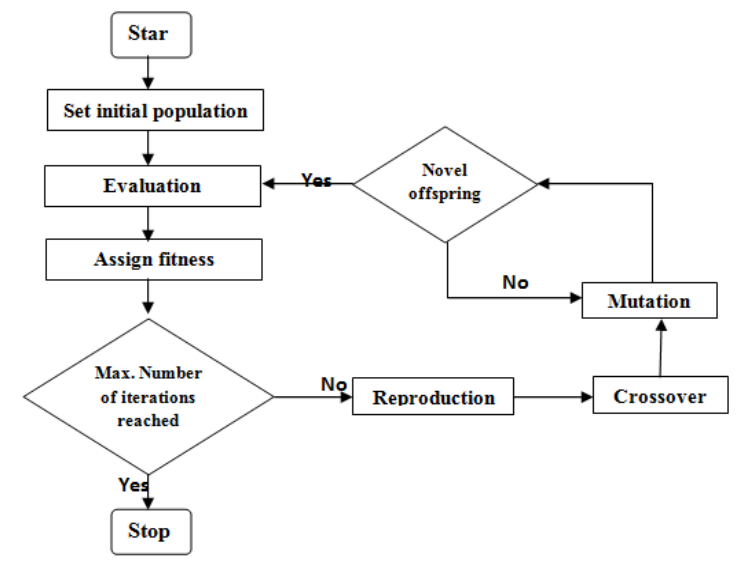

Fig. 1. Genetic Algorithm flowchart for PI Controller Tuning.
The overall system using PID controller is depicted in Figure 2.

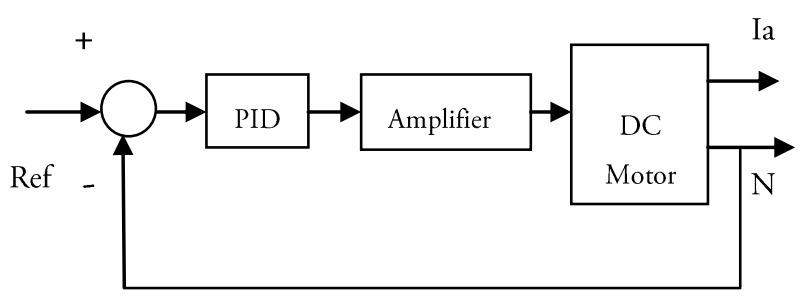

Fig. 2. Overall system using a PID controller

\subsection{LINEAR FUZZY CONTROLLER}

The second step is to replace the summation in PID control by a linear fuzzy controller acting like a summation. The closed loop system should thus show exactly the same step response. The following checklist summarizes the general design choices for achieving a fuzzy rule base equivalent to a summation (see Appendix A):

a. Use triangular input sets that cross at $\mu=0.5$

b. Use algebraic product for and connective.

c. The rule base must be the outer and product of all input families.

d. Use output singletons, positions determined by the sum of peak positions of the input sets.

In order to minimize the size of the rule base, the integral action is separated and performed in the non-fuzzy domain as shown in Figure 3. The integral error is computed as:

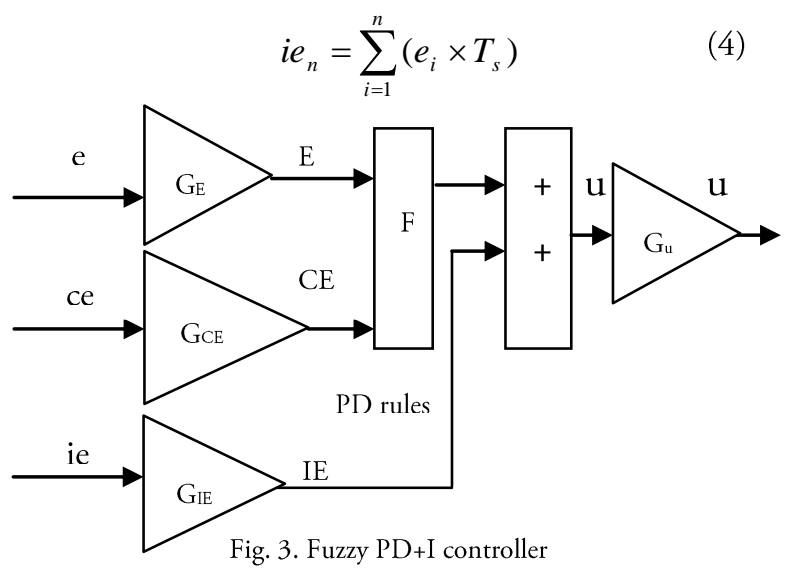


The rule base that contains nine rules is used in this paper are given in Table 1.

TABLE 1 NINE RULES USED IN THIS PAPER.

\begin{tabular}{|c|c|c|c|}
\hline Neg & NB & Zero & Pos \\
\hline Zero & NM & ZE & ZE \\
\hline Pos & ZE & PM & PB \\
\hline
\end{tabular}

The membership functions for the input and output variables are shown in Figures 4 and 5 respectively.

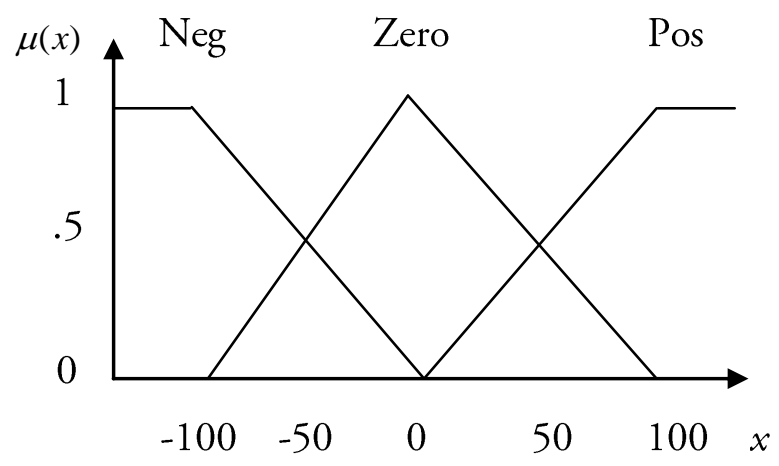

Fig. 4. Membership functions for the inputs error and change of error

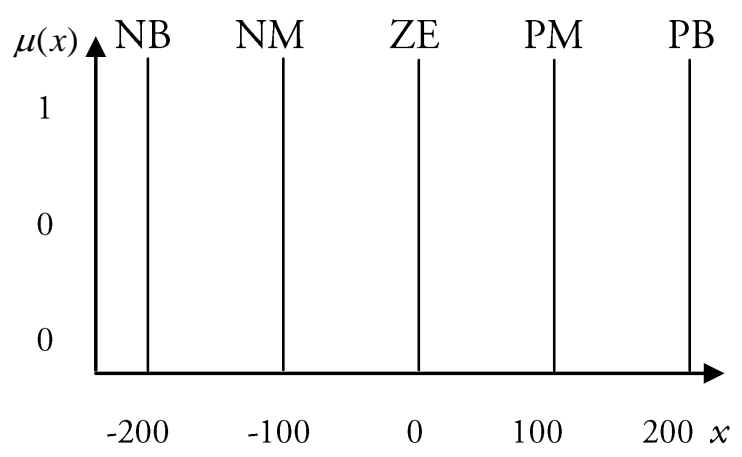

Fig. 5. Membership functions for the singleton output

The controller is thus a function of the three inputs e, ce, and ie as in equation (5)

$$
U_{n}=\left[f\left(G_{E} \times e_{n}, G_{C E} \times c e_{n}\right)+G_{I E} \times i e_{n}\right] \times G_{U}
$$

Its linear approximation is

$$
\begin{aligned}
U_{n} & =\left[G_{E} \times e_{n}+G_{C E} \times c e_{n}+G_{I E} \times i e_{n}\right] \times G_{U} \\
& \left.=G_{U} G_{E} e_{n}+G_{U} G_{C E} \times c e_{n}+G_{U} G_{I E} \times i e_{n}\right]
\end{aligned}
$$

Comparing (3) and (6), the gains are related in the following way:

$$
K_{p}=G_{U} \times G_{E}
$$

$$
\begin{aligned}
& K_{d}=G_{U} \times G_{C E} \\
& K_{i}=G_{U} \times G_{I E}
\end{aligned}
$$

There is one degree of freedom, so, $G_{E}$ is adjusted first according to the universe of discourse to exploit the range fully, and then the other parameters can be computed easily.

\subsection{MAKING THE FUZZY CONTROLLER NONLINEAR}

The third step in the design procedure is to make the fuzzy controller nonlinear. The shape of the sets and the choice of rules affect the control strategy and the dynamics of the closed loop system [4]. It is difficult to make a fair and objective comparison of their control characteristics. One should select a type of surface that fits the problem at hand. It is recommended to start a design procedure with the linear surface and tune the gains and then replace it with a nonlinear surface that is suitable for the system under study.

\subsection{FINE-TUNING THE FUZZY NONLINEAR CONTROLLER}

The forth step is to fine-tune the gains by intuition and experience; if the sampling time is too short, the computation of $c e_{n}$ will become too sensitive to noise. On the other hand, one would choose $G_{E}$ as large as possible to cover the range of the universe exactly. However, an increase in $G_{C E}$ will increase the derivative gain, so one would keep it as small as possible in order to keep noise problems to a minimum. The good choice of $G_{U}$ is very important too. If it is so small, the response will be very slow, hence, one would select it as large as possible without creating too much overshoot. A procedure of hand-tuning a fuzzy $\mathrm{PD}+\mathrm{I}$ controller is the following: 
a. Select a suitable value for $G_{E}$ such that it exploits the range of the universe fully.

b. Set $G_{I E}=G_{C E}=0$

c. Tune $G_{U}$ to give the desired response, ignoring any final value offset.

d. Increase the proportional gain $G_{U}$ and adjust the derivative gain $G_{C E}$ to dampen the overshoot.

e. In order to remove any final value offset, adjust the integral gain $G_{I E}$.

f. Repeat the procedure until $G_{U}$ is as large as possible.

\section{SIMULATION RESULTS}

Numerical values of the parameters of the DC motor are as follows [5]:

\begin{tabular}{|c|c|c|}
\hline$P=5 \mathrm{~kW}$ & $V_{t}=220 \mathrm{~V}$ & $N=1500 \mathrm{rpm}$ \\
\hline$R_{a}=0.5 \Omega$ & $L_{a}=14 \mathrm{mH}$ & $J_{a}=0.15 \mathrm{~kg} . \mathrm{m}^{2}$ \\
\hline
\end{tabular}

$$
\begin{array}{|l|l|}
\hline K=1.4 & D=0.01 N m . s . \\
\hline
\end{array}
$$

Many case studies are selected in order to show the validity of the proposed controller and comparison through classical PID method tuned by GA. The simulation results shown in Figure 5 are carried out as follows: At $(t=0)$, the drive is assumed to operate at steady state with initial load torque corresponding to 0.5 p.u. At $(t=1 \mathrm{~s})$ a step in the speed command amount to 0.1 $p . u$. is simulated, and at $(t=2 \mathrm{~s})$ another step in the load torque corresponding to full load value is also simulated. Figure 6 shows the speed responses for steady state speeds of 1350, 750, and $250 \mathrm{rpm}$ respectively. A separate case corresponding to initial steady state speed of $550 \mathrm{rpm}$ is shown in Figure 7 in order to clarify the details of the response.

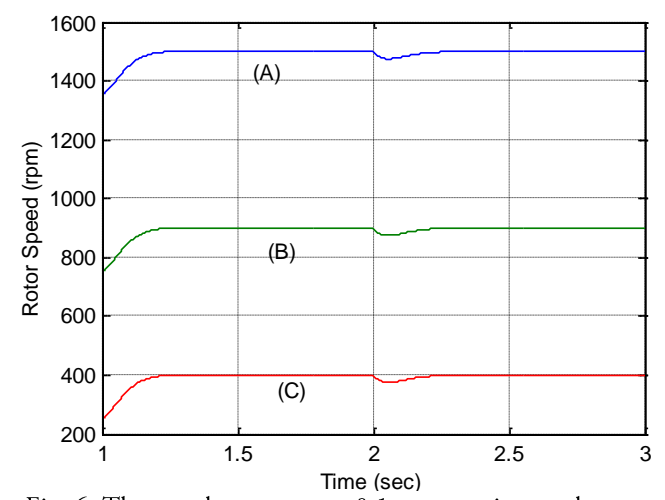

Fig. 6. The speed responses to 0.1 p.u. step in speed command with initial s.s. speeds of (A) $1350 \mathrm{rpm}$, (B) $750 \mathrm{rpm}$, and (C) 250 rpm.

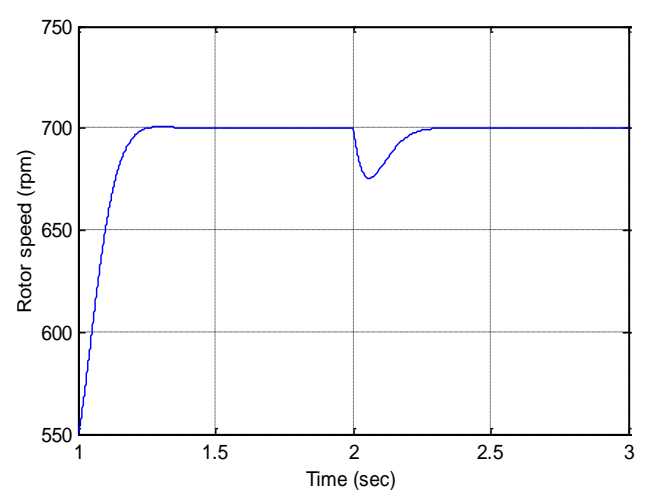

Fig. 7. A separate simulation case with initial steady state speed of $550 \mathrm{rpm}$.

The results show that the proposed controller provides relatively fast and nonoscillatory speed response with small settling time. Only a dip in speed response results when changing the load torque from 0.5 p.u. to full load. Another test is taken as an example for the parameters variations of the system. This situation is a simulation in the case of increasing the inertia to double its value due to the added inertia of the load to that of the motor. Figure 8 shows the speed responses for steady state speeds of 1350 , 750 , and $250 \mathrm{rpm}$ respectively with doubling the inertia. Also, a case corresponding to initial steady state speed of $550 \mathrm{rpm}$ with double inertia is dropped out and is shown in Figure 9 for more details. It is shown that the proposed controller has modified its action as a result to this 
parameters variation. This assures the robustness of the proposed controller.

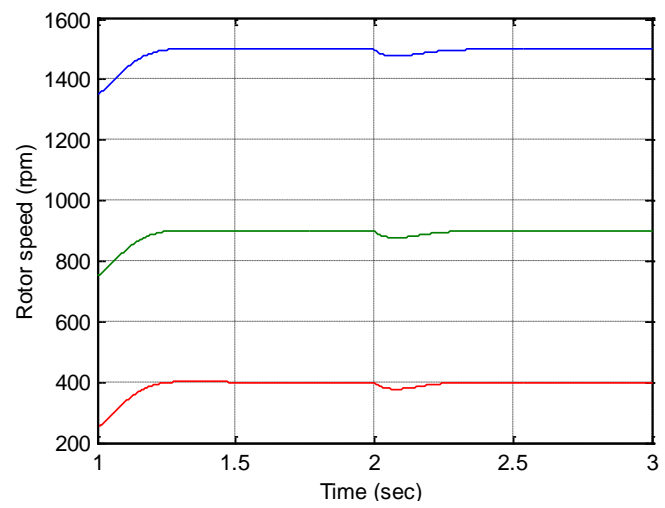

Fig. 8. The responses to 0.1 p.u. step in speed command when the drive operates at double its normal inertia

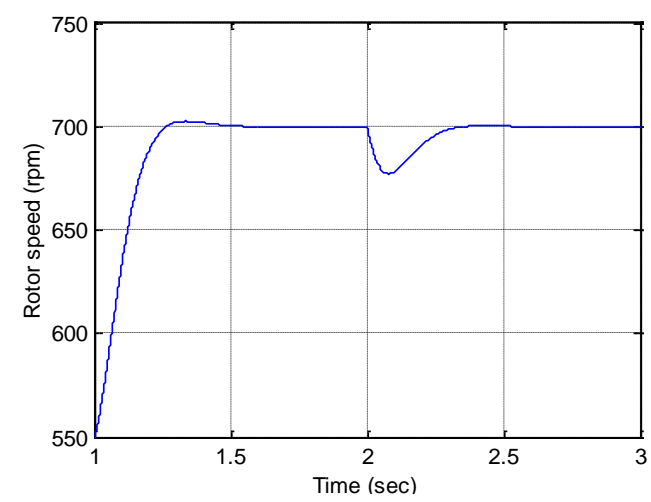

Fig. 9. A separate simulation case with initial steady state speed of $550 \mathrm{rpm}$ and double inertia

The output of the fuzzy controller as well as the integral controller output is shown in Figures 10 and 11 for the case with initial speed of $1350 \mathrm{rpm}$ and rated inertia.

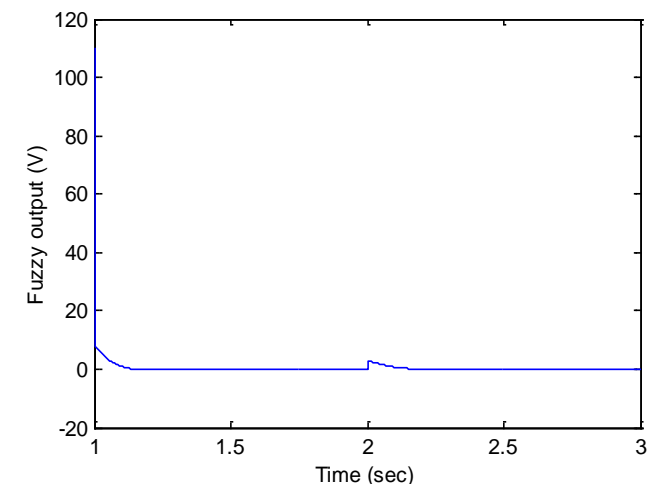

Fig. 10. The output of the fuzzy controller with initial speed of $1350 \mathrm{rpm}$

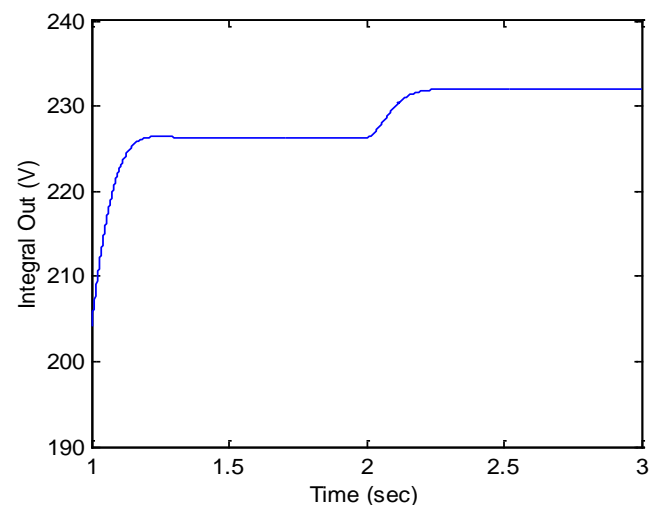

Fig. 11. The output of the integral controller and corresponding to initial s.s. speed of $1350 \mathrm{rpm}$.

It can be noted that the PD fuzzy controller plays its main role in transient periods, while it resets its output at the steady state periods leaving the separated integral controller to perform its mission. Also, the armature voltage and armature current curves are illustrated in Figure 12 and 13 for the case of $1350 \mathrm{rpm}$ initial speed and rated inertia.

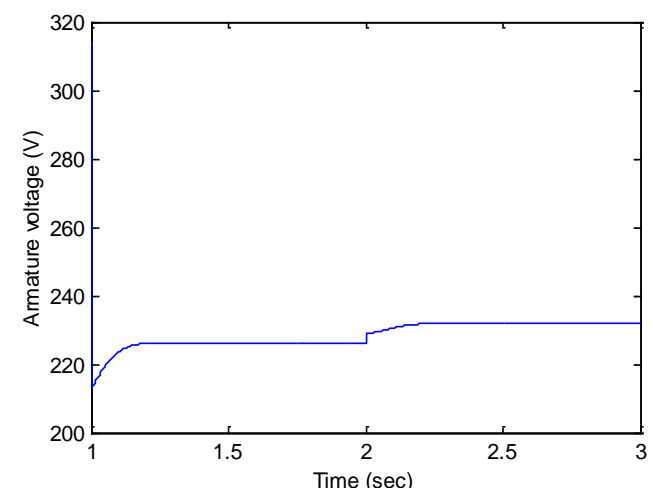

Fig. 12. The armature voltage response at steady state speed of $1350 \mathrm{rpm}$

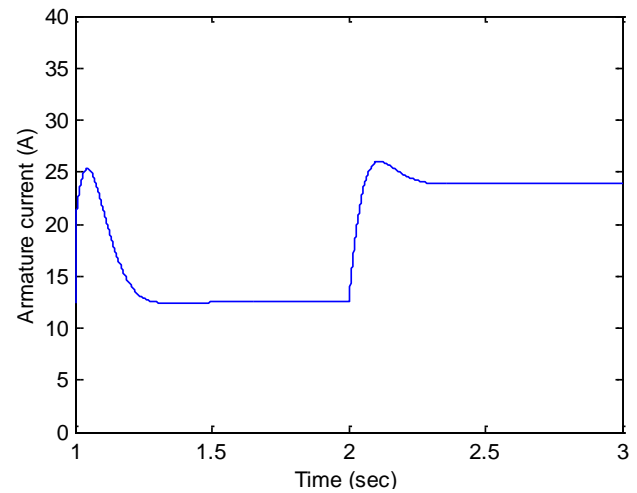

Fig. 13. The armature current response at initial steady state speed of $1350 \mathrm{rpm}$ 


\section{CONCLUSION}

DC motor drive using Fuzzy PD+I controller is introduced in this paper to control the motor speed. Fine tuning of PID controller with GA in applied to minimize the ISE to obtain optimal PID control parameters. The optimal values for classical PID controller parameters obtained by GA are set to be the initial values for tuning $\mathrm{PI}+\mathrm{D}$ fuzzy controller in the transformation of classical PID into Fuzzy PD+I controller. With some modification and rules applied, the proposed DC motor drive control can be operated in both non-linear and linear modes. Many cases are studied including the operation with different starting steady state speeds, changing the system parameters, and abrupt load change. Both the control voltage and the armature current responses ensure the healthy operation of the combined fuzzy PD+I controller. The obtained results show that the controller provides fast and non-oscillatory speed responses and it helps in paving the way to improve the performance of the existing analog controllers which are present in most of the process in industry.

\section{REFERENCES}

[1] S. Li and R. Challoo, "Restructuring an electric machinery course with an integrative approach and computer-assisted teaching methodology," IEEE Transactions on Education., vol. 49, pp. 16-28, Feb. 2006.

[2] D. A. Staton, M. I. McGilp and T. J. E. Miller, "DC machine teaching experiment," in Proceedings of the European Power Electronics Association EPE, Brighton, pp. 35-40,1993.

[3] S. Abe and M. S. Lan, "A method for fuzzy rules extraction directly from numerical data and its application to pattern classification," IEEE Trans. Fuzzy Syst., vol. 3, pp. 353-361, Feb. 1995.
[4] W. Pedrycz and M. Reformat, "Rule based modeling of nonlinear relationships," IEEE Trans. Fuzzy. Syst., vol. 5, pp. 256-269, May 1997.

[5] C.-T. Sun, "Rule base structure identification in an adaptive network based fuzzy inference system," IEEE Trans. Fuzzy Syst., vol. 2, pp. 64-73, Apr. 1994.

[6] Rajani K. Mudi, and Nikhil R. Pal., "A Robust Self-Tuning Scheme for PI- and PD- Type Fuzzy Controllers", IEEE Transactions on Fuzzy Systems. Vol. No. 7 Feb. 1999

[7] Jantzen J., "Tuning of Fuzzy PID Controllers", Tech. report no 98-H 871 (fpid), 30 Sep 1998.

[8] Baogang $\mathrm{Hu}$, George K. I. Mann, and Raymond G. Gosine, "New Methodology for Analytical and Optimal Design of Fuzzy PID Controllers", IEEE Transactions on Fuzzy Systems. Vol. No. 5 October 1999.

[9] Jantzen J., "A Robustness Study of Fuzzy Control Rules", Proceedings Fifth European Congress on Fuzzy and Intelligent Technologies, 1997.

[10] Saleh Kh. I., and Benamrouche N., "Simulation of dc Motor Drives Equipped with a Fuzzy Logic PID-Equivalence Speed Controller", STCEX, Riyadh, October 2002.

[11] Mohammed. I. Mosaad and F. Salem "LFC Based Adaptive PID Controller Using ANN and ANFIS Techniques" Journal of Electrical Systems and Information Technology, vol. 1, no. 3, pp. 212-222, Dec. 2014.

[12] Mohamed I. Mosaad, M Azab and A. Abu Siada "Transformer Parameter Estimation from Nameplate Data Using Evolutionary Programming Techniques" IEEE Transactions On Power Delivery, Vol. 29, No. 5, 2014.

[13] Mohamed I. Mosaad , M Azba and A.Abu Siada "A Novel Evolutionary Technique to Estimate Induction Machine Parameters from Name Plate Data” ICEM'2016 SwissTech Convention Center Lausanne - Switzerland, September 4-7, 2016. 


\section{APPENDIX (A)}

Assume both inputs, $E$ and $C E$, are defined on a standard universe $[-100,100]$ as shown in Figure (A-1)

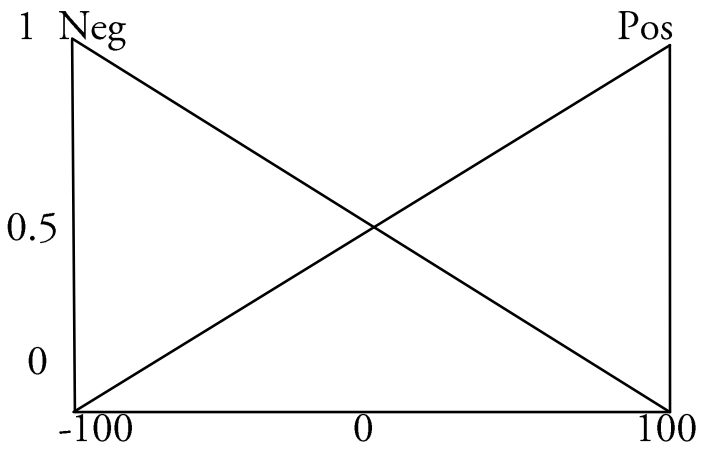

Fig. A-1. Membership function for both $E$ and $C E$

The sum of the membership values for each input is "1" which can be achieved when the sets are triangular and cross their neighbor sets at the membership value $\mu=0.5$. Any input value can thus be a member of at most two sets and the membership of each is a linear function of the input value. The output sets should preferably be singletons $s_{i}$, since it simplifies the defuzzification. The rule base can be defined as in Table A.1.

TABle A.1 THE RUlE BASED

\begin{tabular}{|c|c|c|}
\hline $\mathrm{E}-C E$ & Pos & $\mathrm{Neg}$ \\
\hline Pos & $s_{1}$ & $s_{2}$ \\
\hline $\mathrm{Neg}$ & $s_{3}$ & $s_{4}$ \\
\hline
\end{tabular}

Referring to the rule base, the contribution to the control signal from the first rule is

$$
\mu_{1} \times s_{1}=\mu_{P o s}(E) \wedge \mu_{P o s}(C E) \times s_{1}
$$

To ensure linearity, we must choose the algebraic product for the connective and, i.e.

$$
\mu_{1} \times s_{1}=\mu_{P o s}(E) \times \mu_{P o s}(C E) \times s
$$

The combination of all contributions, using COA defuzzification is

$$
u=\frac{\mu_{1} \times s_{1}+\mu_{2} \times s_{2}+\mu_{3} \times s_{3}+\mu_{4} \times s_{4}}{\mu_{1}+\mu_{2}+\mu_{3}+\mu_{4}+}
$$

To simplify the notation, we will substitute

$$
\begin{aligned}
& x=\mu_{P o s}(E), 1-x=\mu_{N e g}(E) \\
& y=\mu_{P o s}(C E), 1-y=\mu_{N e g}(C E)
\end{aligned}
$$

Notice that the denominator of $(\mathrm{A}-3)$ is

$$
x y+x(1-y)+(1-x) y+(1-x)(1-y)
$$

It is clear from (A-5) that the denominator of (A-3) is "1". This means that it doesn't affect the calculations. However, the numerator is completely different,

$$
\begin{aligned}
N(E, C E)= & \mu_{1} \times s_{1}+\mu_{2} \times s_{2}+ \\
& \mu_{3} \times s_{3}+\mu_{4} \times s_{4} \\
& =x y s_{1}+x(1-y) s_{2}+ \\
& (1-x) y s_{3}+(1-x)(1-y) s_{4}
\end{aligned}
$$

Clearly $x, y \in[0,1]$ since they are really fuzzy membership functions, and (A-6) is simply a bilinear interpolation between the four scalars $s_{1}, s_{2}, s_{3}$, and $s_{4}$. Since $x$ is a linear function in $E$ and $y$ is a linear function in $C E$, the numerator $N(E, C E)$, and thereby the controller output $U_{n}$, is a bilinear function in $E$ and $C E$. When $(x, y)=(1,1)$, all other terms but the one holding $s_{1}$ are zero, and when $(x, y)=(1,0)$, all other terms but the one holding $s_{2}$ are zero, etc. Since $(x, y)=(1,1)$ when $(E, C E)=(100,100)$, then $s_{1}$ should be chosen to be 200 in order to obtain the sought equivalence with the summation $E+C E$. The rest of the singletons should be chosen in a similar way, yielding

$$
\left(s_{1}, s_{2}, s_{3}, s_{4}\right)=(200,0,0,-200)
$$

What has been said can be generalized to input families with more than two input sets per input, because only two input sets will be active at a time. 
By this way, we can obtain a linear control surface like this of Figure (A-2).

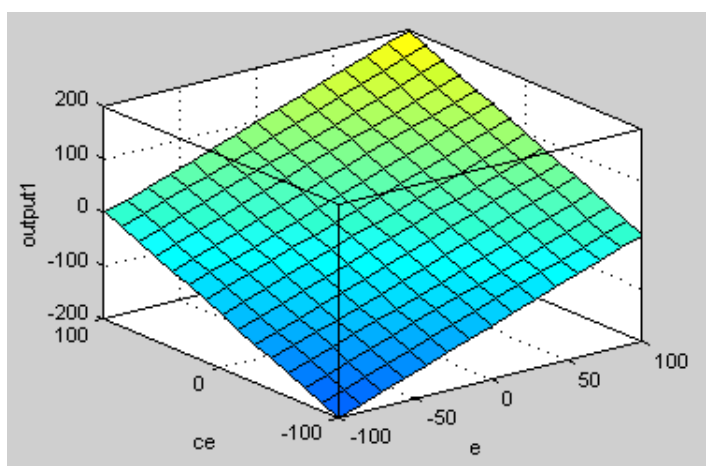

Fig. A-2. The linear control surface 


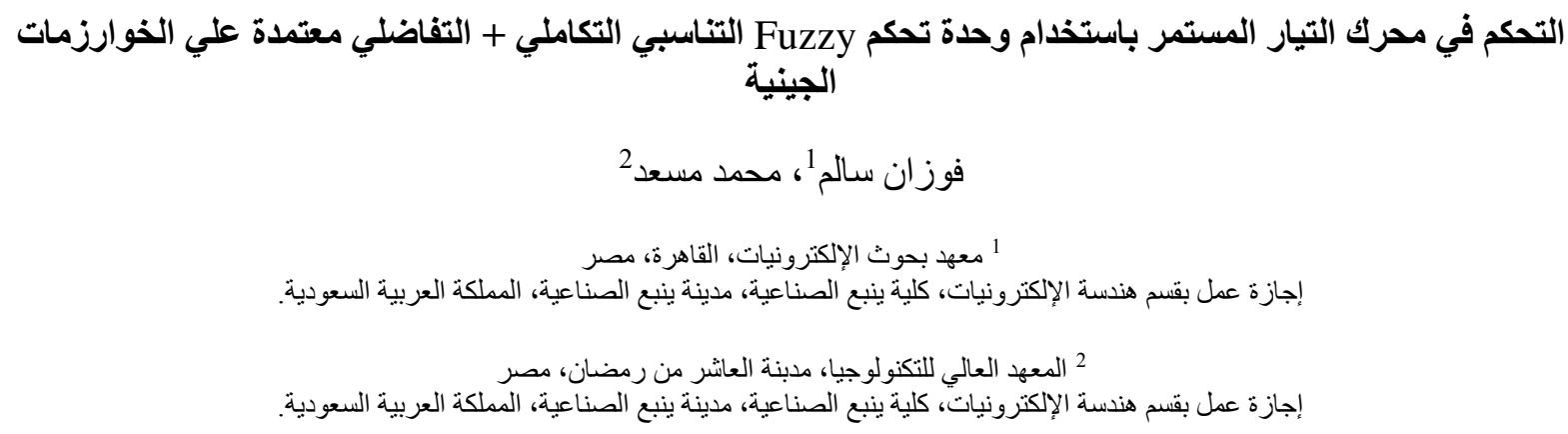

الملخص:

تقدم هذه المقالة طريقة تحكم لمحرك تيار مستمر باستخدام وحدة تحكم Fuzzy التناسبي التكاملي +التفاضلي مبنية علي الخوارزمات الجينية. طريقة التحكم هذه مناسبة عندما تكون هناك إمكانية تطبيق وحدة تحكم التناسبي التكاملي التفاضلي ـ و الفكرة وراء هذا المتحكم هي ضبط معاملات التحكم التقليدية (التناسبي التكاملي التفاضلي) باستخدام الخوارزمات الجينية ثم حساب ما يكافئها في مجال Fuzzy ـ وقد إستخدمت المعاملات المضبوطة هذه كقيم أولية لمعلمات وحدة التحكم Fuzzy التناسبي التكاملي +التفاضلي. وحدة التحكم الجديدةالمقترحة، Fuzzy التناسبي التكاملي +التفاضلي، تم تطبيقها للتحكم في سرعة محرك تيار مستمر على مدى واسع من سرعات التشغيل. و علاوة على ذلك، فإن المتحكم المقترح نجح في تحسين أداء النظام حتى مع تغيير معاملات النظام. 